REVIEW

\title{
Justified and unjustified use of growth hormone
}

\section{A J van der Lely}

Postgrad Med J 2004;80:577-580. doi: 10.1136/pgmi.2003.017467

Growth hormone (GH) replacement therapy for children and adults with proven $\mathrm{GH}$ deficiency due to a pituitary disorder has become an accepted therapy with proven efficacy. GH is increasingly suggested, however, as a potential treatment for frailty, osteoporosis, morbid obesity, cardiac failure, and various catabolic conditions. However, the available placebo controlled studies have not reported many significant beneficial effects, and it might even be dangerous to use excessive $\mathrm{GH}$ dosages in conditions in which the body has just decided to decrease $\mathrm{GH}$ actions. $\mathrm{GH}$ can indeed induce changes in body composition that are considered to be advantageous to $\mathrm{GH}$ deficient and non-GH deficient subjects. In contrast to $\mathrm{GH}$ replacement therapy in $\mathrm{GH}$ deficient subjects, however, excessive $\mathrm{GH}$ action due to $\mathrm{GH}$ misuse seems to be ineffective in improving muscle power. Moreover, there are no available study data to indicate that the use of $\mathrm{GH}$ for non-GH deficient subjects should be advocated, especially as animal data suggest that lower GH levels are positively correlated with longevity.

Correspondence to:

Dr A J van der Lely Department of Internal Medicine, Erasmus MC, 40 Dr Molewaterplein, 3015 GD Rotterdam, The Netherlands; a.vanderlelii @erasmusmc.nl

Submitted

21 November 2003

Accepted

25 February 2004
$\mathrm{T}$ he therapeutic use of growth hormone $(\mathrm{GH})$ as replacement in $\mathrm{GH}$ deficient adults has been shown to produce a beneficial effect on body composition, serum lipid concentrations, bone mineral density, muscle strength, and exercise endurance. It remains to be determined, however, whether or not chronic GH replacement therapy will indeed have beneficial effects on morbidity and mortality. The benefits of chronic use of $\mathrm{GH}$ for other potential indications such as ageing, catabolism, diabetes, and morbid obesity is far from clear.

However, GH is also used for conditions in which no intrinsic disease is present, for example, cosmetic use for slight adiposity and sports use to improve performance. Obviously, the use medical profession, and indeed can have significant and potentially dangerous side effects. In the following sections, an overview is given of the accepted indication for use of daily $\mathrm{GH}$ injections, as well as an overview on the misuse of this powerful peptide hormone.

\section{JUSTIFIED USE OF GROWTH HORMONE In children}

In paediatrics, there is no doubt that the use of recombinant human GH for short stature has been very successful. The improved final height for these children has been increased of $\mathrm{GH}$ for these goals is not promoted by the dramatically, with a corresponding increase in quality of life. ${ }^{12}$ There is also a place for $\mathrm{GH}$ in the management of children with other conditions associated with GH deficiency or lack of GH action, such as Turner's syndrome and chronic renal insufficiency. ${ }^{12}$ Treatment with GH in combination with low dose oestrogens can result in a significant increase in adult height in girls with Turner's syndrome, even if they start the treatment at a relatively late age. ${ }^{5}$ Children with hypochondroplasia having severe short stature and disproportion of the body segments owing to the mutation Asn540Lys respond to GH therapy with an increase in spinal length, and in combination with a surgical leg lengthening procedure it is possible for some patients even to achieve an adult height within the normal range. ${ }^{6}$ At present, there is no way of predicting which patient with hypochondroplasia will undergo a normal pubertal growth spurt, therefore, all such patients should be monitored during childhood and GH treatment should be only be given to those patients who fail to develop a growth spurt at puberty. ${ }^{6}$

Severe growth retardation can also be observed in children treated with glucocorticoids for conditions such as systemic forms of juvenile chronic arthritis. Studies suggest that GH may partially counteract such adverse effects of glucocorticoids on growth and metabolism in patients with chronic inflammatory diseases, but more long term controlled studies are needed to determine the risks and benefits of GH therapy in this subgroup of $\mathrm{GH}$ deficient patients. ${ }^{7}$

\section{In adults}

The beneficial effects of chronic replacement therapy in GH deficient adult patients have been addressed by many studies. Because of the existence of several large databases, we are able to show beneficial improvements with GH therapy not only in quality of life, cardiac performance, and anthropomorphic parameters such as body composition, but also on many biochemical parameters such as lipid patterns, coagulation, and glucose metabolism. ${ }^{3}{ }^{8-16}$

Elderly patients with end stage renal disease, who often have protein and/or caloric malnutrition that severely affects general wellbeing and mortality, also benefit from GH therapy. It was reported that GH treatment increased serum insulin-like growth factor-1 (IGF-1), fat free mass, and serum concentration of albumin compared with placebo, while the number of patients with hypoalbuminaemia was reduced by a factor of three in the GH treated group. ${ }^{3} \mathrm{~A}$

Abbreviations: GH, growth hormone; IGF-1, insulin-like growth factor-1; IGFBP, insulin-like growth factor binding protein 
Growth hormone treatment is recommended for children with proven clinical diagnosis of GH deficiency and for children with Turner's syndrome. It is also recommended for prepubertal children with chronic renal failure. (Source: National Institute for Clinical Excellence; Technology Appraisal Guidance No 42.)
Growth hormone treatment is recommended for adults with severe growth hormone deficiency, provided that they have a perceived impairment in quality of life and that they are already receiving treatment for any other pituitary hormone deficiencies as required. (Source: National Institute for Clinical Excellence; Technology Appraisal Guidance No 64.)

one of the most popular potentially performance enhancing drugs used by athletes. The lack of an official test for GH misuse, together with the widespread rumours of its tremendous beneficial effects seem to make this compound attractive for athletes. Promising methods for detection of GH misuse have been developed, but have yet to be sufficiently well validated to be ready for introduction into competitive sport. ${ }^{29}$ There is a futher complication; an Italian athlete who won a gold medal at the Sydney Olympic Games was accused of using performance enhancing drugs after the finding of high levels of plasma GH before the Games. Following the accusation, she was studied under stressed and unstressed conditions. Under stressed conditions, GH levels were above the normal range in all blood samples, whereas IGF-1 was normal. Under unstressed conditions, GH progressively returned to accepted normal levels and again IGF-1 was normal. Therefore, the normal range for GH in athletes might have to be reconsidered if used for detection of performance enhancers, as athletes are by definition subject to stress and thus apparently, to wide variations in GH levels. ${ }^{30}$

Interestingly, Coschigano and co-workers observed that mice homozygous for the disruption of the GH receptor lived significantly longer. ${ }^{31} 32$ The extension of lifespan in these animals was very large (up to 65\%), reproducible, and not limited to any particular genetic background or husbandry conditions. These findings suggest that GH may have an important role in the determination of lifespan. Studies using Ames, Snell, and GH receptor knockout models have concluded that decreased GH and IGF-1 levels are closely correlated with an increased life span. ${ }^{32-35}$ Additionally, studies indicating that taller people are more productive than shorter have ignored a wide range of evidence that shorter people live longer. ${ }^{32}{ }^{36-44}$

Despite this, the assumption that hormonal therapy is a potential "fountain of youth" seems logical, as the diminished secretion of GH is responsible in part for the decrease in lean body mass, the expansion of adipose tissue mass, and the thinning of the skin that occur in old age. ${ }^{45}$ At present, however, the effects of GH in healthy elderly men have been studied in only a few randomised placebo controlled trials, ${ }^{46-48}$ and the effects of GH therapy on muscle strength, on metabolic and sexual function, and on skeletal homoeostasis were not consistent. ${ }^{46-49}$ When GH therapy is applied in the elderly as a potential fountain of youth, it must be realised that not only the GH concentration, but levels of IGF-1, insulin, and insulin-like growth factor binding protein (IGFBP)-3 change. ${ }^{49-55}$ This is especially important, as some data indicate that high serum IGF-1 levels in combination

There is no justification for the use of growth hormone in non$\mathrm{GH}$ deficient subjects. This includes use in ageing, but otherwise healthy subjects, and the misuse of $\mathrm{GH}$ in subjects in an attempt to improve muscle mass and (or) strength. The use of $\mathrm{GH}$ in severely diseased patients in an intensive care setting has been shown to be dangerous.

After the summer Olympic Games in Sydney, there were number of articles in the press that suggested that GH is now 
with low serum IGFBP-3 concentrations might increase the risk of cancer. ${ }^{53-56}$

\section{CONCLUSIONS}

Growth hormone replacement therapy for children and adults with proven GH deficiency due to a pituitary disorder has become an accepted therapy with proven efficacy. In children with short stature due to other conditions, GH therapy is also often successful. In GH deficient adults with increased body fat and reduced muscle mass, and consequently reduced strength and exercise tolerance, GH therapy has also proven to be a successful method to improve quality of life, and to reverse many anomalies. GH has also been considered for the therapeutic treatment of frailty, osteoporosis, morbid obesity, cardiac failure, and various acute and chronic catabolic conditions. However, the available placebo controlled studies have not reported many significant beneficial effects. Furthermore, after a report on an increase in mortality in critically ill patients receiving large doses of $\mathrm{GH}$, the official use of GH in non-GH deficient adult patients has been reduced to almost zero.

$\mathrm{GH}$ can induce changes in body composition that are considered to be advantageous to ageing subjects and sportsmen. However, there are no results that indicate that the use of $\mathrm{GH}$ for these individuals should be advocated, because of the lack of any proven efficacy for improved performance. Moreover, animal data suggest that higher GH levels are negatively correlated with longevity.

\section{REFERENCES}

1 Fine RN, Sullivan EK, Tejani A. The impact of recombinant human growth hormone treatment on final adult height. Pediatr Nephrol 2000;14:679-81.

2 Frindik JP, Baptista J. Adult height in growth hormone deficiency: historical perspective and examples from the national cooperative growth study. Pediatrics 1999; 104:1000-4

3 Johannsson G, Bengtsson BA, Ahlmen J. Double-blind, placebo-controlled study of growth hormone treatment in elderly patients undergoing chronic hemodialysis: anabolic effect and functional improvement. Am J Kidney Dis 1999;33:709-17.

4 Janssen F, Damme-Lombaerts R, Van Dyck M, et al. Impact of growth hormone treatment on a Belgian population of short children with renal allografts. Pediatr Transplant 1997:1:190-6.

5 Sas TC, Muinck Keizer-Schrama SM, Stijnen T, et al. Final height in girls with Turner's syndrome treated with once or twice daily growth hormone injections. Dutch Advisory Group on Growth Hormone. Arch Dis Child 1999;80:36-41.

6 Ramaswami U, Hindmarsh PC, Brook CG. Growth hormone therapy in hypochondroplasia. Acta Paediatr 1999;88(suppl): $116-17$.

7 Simon D, Touati G, Prieur AM, et al. Growth hormone treatment of short stature and metabolic dysfunction in juvenile chronic arthritis. Acta Paediatr Suppl 1999;88:100-5.

8 Deijen JB, van der Veen EA. The influence of growth hormone (GH) deficiency and $\mathrm{GH}$ replacement on quality of life in $\mathrm{GH}$-deficient patients. J Endocrinol Invest 1999;22:127-36.

9 Abs R, Bengtsson B, Hernberg S, et al. GH replacement in 1034 growth hormone deficient hypopituitary adults: demographic and clinical characteristics, dosing and safety. Clin Endocrinol (Oxf) 1999;50:703-13.

10 Svensson J, Johannsson G, Bengtsson BA. Body composition and quality of life as markers of the efficacy of growth hormone replacement therapy in adults. Horm Res 2001;55(suppl 2):55-60.

11 Johannsson G, Svensson J, Bengtsson BA. Growth hormone and ageing. Growth Horm IGF Res 2000;10(suppl B):S25-30.

12 Bengtsson BA, Abs $\mathrm{R}$, Bennmarker $\mathrm{H}$, et al. The effects of treatment and the individual responsiveness to growth hormone $(G H)$ replacement therapy in $665 \mathrm{GH}$-deficient adults. KIMS Study Group and the KIMS International Board. J Clin Endocrinol Metab 1999;84:3929-35.

13 Rosen T, Bengtsson BA. Premature mortality due to cardiovascular disease in hypopituitarism. Lancet 1990;336:285-8.

14 Kehely A, Bates PC, Frewer P, et al. Short-term safety and efficacy of human GH replacement therapy in 595 adults with $\mathrm{GH}$ deficiency: a comparison of two dosage algorithms. J Clin Endocrinol Metab 2002;87:1974-9.

15 Herschbach P, Henrich G, Strasburger CJ, et al. Development and psychometric properties of a disease-specific quality of life questionnaire for adult patients with growth hormone deficiency. Eur J Endocrinol $2001 ; 145: 255-65$.

16 Colao A, Di Somma C, Pivonello R, et al. The cardiovascular risk of adult GH deficiency (GHD) improved after $\mathrm{GH}$ replacement and worsened in untreated GHD: a 12-month prospective study. J Clin Endocrinol Metab 2002;87:1088-93.
17 Takala J, Ruokonen E, Webster NR, et al. Increased mortality associated with growth hormone treatment in critically ill adults. N Engl J Med 1999;341:785-92.

18 Kissmeyer-Nielsen $\mathbf{P}$, Jensen MB, Laurberg S. Perioperative growth hormone treatment and functional outcome after major abdominal surgery: a randomized, double-blind, controlled study. Ann Surg 1999;229:298-302.

19 Barry MC, Mealy K, Sheehan SJ, et al. The effects of recombinant human growth hormone on cardiopulmonary function in elective abdominal aortic aneurysm repair. Eur J Vasc Endovasc Surg 1998;16:311-19.

20 van der Lely AJ, Lamberts SW, Jauch KW, et al. Use of human GH in elderly patients with accidental hip fracture. Eur J Endocrinol 2000;143:585-92.

21 Schambelan M, Mulligan K, Grunfeld C, et al. Recombinant human growth hormone in patients with HIV-associated wasting. A randomized, placebocontrolled trial. Serostim Study Group. Ann Intern Med 1996;125:873-82

22 Frisch $\mathrm{H}$. Growth hormone and body composition in athletes. J Endocrinol Invest 1999;22:106-9.

23 Hulthen L, Bengtsson BA, Sunnerhagen KS, et al. GH is needed for the maturation of muscle mass and strength in adolescents. J Clin Endocrinol Metab 2001;86:4765-70.

24 Janssen YJ, Doornbos J, Roelfsema F. Changes in muscle volume, strength, and bioenergetics during recombinant human growth hormone $(\mathrm{GH})$ therapy in adults with GH deficiency. J Clin Endocrinol Metab 1999;84:279-84.

25 Jorgensen JO, Vahl N, Hansen TB, et al. Growth hormone versus placebo treatment for one year in growth hormone deficient adults: increase in exercise capacity and normalization of body composition. Clin Endocrinol (Oxf) 1996;45:681-8.

26 Macintyre JG. Growth hormone and athletes. Sports Med 1987;4:129-42.

27 Bowers LD. Abuse of performance-enhancing drugs in sport. Ther Drug Monit 2002;24:178-81

28 Congeni J, Miller S. Supplements and drugs used to enhance athletic performance. Pediatr Clin North Am 2002:49:435-61.

29 Wu Z, Bidlingmaier M, Dall R, et al. Detection of doping with human growth hormone. Lancet 1999;353:895

30 Armanini D, Faggian D, Scaroni C, et al. Growth hormone and insulin-like growth factor I in a Sydney Olympic gold medallist. Br J Sports Med 2002;36:148-9.

31 Coschigano KT, Clemmons D, Bellush LL, et al. Assessment of growth parameters and life span of GHR/BP gene-disrupted mice. Endocrinology 2000;141:2608-13.

32 Bartke A, Coschigano K, Kopchick J, et al. Genes that prolong life: relationships of growth hormone and growth to aging and life span. J Gerontol A Biol Sci Med Sci 2001;56:B340-9.

33 Carter CS, Ramsey MM, Ingram RL, et al. Models of growth hormone and IGF1 deficiency: applications to studies of aging processes and life-span determination. J Gerontol A Biol Sci Med Sci 2002;57:B177-88.

34 Rose MR. Can human aging be postponed? Sci Am 1999;281:106-11.

35 Kalu DN, Orhii PB, Chen C, et al. Aged-rodent models of long-term growth hormone therapy: lack of deleterious effect on longevity. J Gerontol A Biol Sci Med Sci 1998;53:B452-63.

36 Samaras T, Elrick H, Storms LH. Height, health and growth hormone. Acta Paediatr 1999:88:602-9.

37 Frederiksen $\mathbf{H}$, McGue $M$, Jeune B, et al. Do children of long-lived parents age more successfully? Epidemiology 2002; 13:334-9.

38 Taira K, Tanaka H, Arakawa M, et al. Sleep health and lifestyle of elderly people in Ogimi, a village of longevity. Psychiatry Clin Neurosci 2002; 56:243-4

39 Barzilai N, Shuldiner AR. Searching for human longevity genes: the future history of gerontology in the post-genomic era. J Gerontol A Biol Sci Med Sci 2001; 56:M83-7.

40 Cassel CK. Successful aging. How increased life expectancy and medical advances are changing geriatric care. Geriatrics 2001;56:35-9.

41 Promislow DE. On size and survival: progress and piffalls in the allometry of life span. J Gerontol 1993:48:B1 15-23.

42 Samaras $\Pi$, Storms LH. Impact of height and weight on life span. Bull World Health Organ 1992;70:259-67.

43 Johansson S. Longevity in women. Cardiovasc Clin 1989;19:3-16.

44 Simopoulos AP, Van Itallie TB. Body weight, health, and longevity. Ann Intern Med 1984;100:285-95.

45 Rudman D, Feller AG, Nagraj HS, et al. Effects of human growth hormone in men over 60 years old. N Engl J Med 1990;323:1-6.

46 Cuttica CM, Castoldi L, Gorrini GP, et al. Effects of six-month administration of recombinant human growth hormone to healthy elderly subjects. Aging (Milano) 1997;9:193-7

47 Lange KH, Isaksson F, Juul A, et al. Growth hormone enhances effects of endurance training on oxidative muscle metabolism in elderly women. Am J Physiol Endocrinol Metab 2000;279:E989-96.

48 Butterfield GE, Thompson J, Rennie MJ, et al. Effect of rhGH and rhlGF-I treatment on protein utilization in elderly women. Am J Physiol 1997;272:E94-9.

49 Janssens $\mathbf{H}$, Vanderschueren DM. Endocrinological aspects of aging in men: is hormone replacement of benefit? Eur J Obstet Gynecol Reprod Biol 2000;92:7-12

50 Savine $\mathbf{R}$, Sonksen PH. Is the somatopause an indication for growth hormone replacement? J Endocrinol Invest 1999;22:142-9.

51 von Werder $\mathbf{K}$. The somatopause is no indication for growth hormone therapy. J Endocrinol Invest 1999;22:137-41.

52 Chipman JJ, Attanasio AF, Birkett MA, et al. The safety profile of $\mathrm{GH}$ replacement therapy in adults. Clin Endocrinol (Oxf) 1997;46:473-81. 
$53 \mathrm{Ma} J$ Pollak MN, Giovannucci E, et al. Prospective study of colorectal cancer risk in men and plasma levels of insulin-like growth factor (IGF)-I and IGFbinding protein-3. J Natl Cancer Inst 1999;91:620-5.

54 Hankinson SE, Willett WC, Colditz GA, et al. Circulating concentrations of insulin-like growth factor-I and risk of breast cancer. Lancet

1998:351:1393-6.
55 Chan JM, Stampfer MJ, Giovannucci E, et al. Plasma insulin-like growth factor-I and prostate cancer risk: a prospective study. Science 1998;279:563-6.

56 Swerdlow AJ, Higgins CD, Adlard P, et al. Risk of cancer in patients treated with human pituitary growth hormone in the UK, 1959-85: a cohort study. Lancet 2002;360:273-7.

\section{IMAGES IN MEDICINE}

\section{Tuberous sclerosis associated with giant bilateral bleeding angiomyolipomas}



Figure 1 Abdominal computed tomogram showing giant bilateral renal masses consisting predominantly of fat tissue, and a retroperitoneal haematoma.

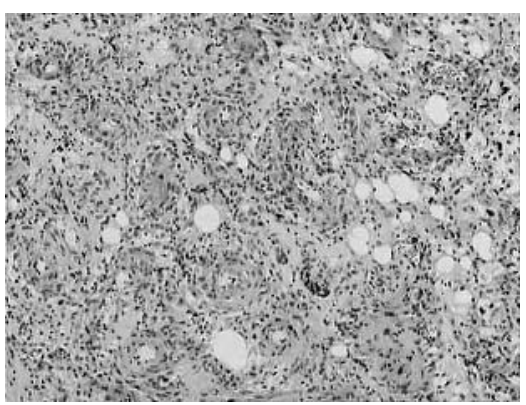

Figure 2 Histological specimen showing a typical renal angiomyolipoma (haematoxylin and eosin $\times 200$ ).

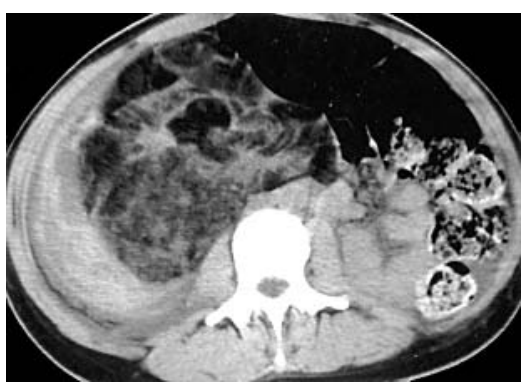

Figure 3 Abdominal computed tomogram showing a giant bleeding right renal angiomyolipoma. uberous sclerosis is a systemic disorder characterised by benign hamartomatous tumours that involve multiple organ systems. Angiomyolipomas are found in about two thirds of the kidneys of patients with tuberous sclerosis at necropsy. ${ }^{1}$

A 29 year old woman with tuberous sclerosis presented with diffuse abdominal pain, gross haematuria, and hypotension. At the age of 22 the patient had been admitted to our hospital with acute upper abdominal pain and gross haematuria. Physical examination had revealed bilateral massive abdominal masses with no tenderness. Computed tomography had confirmed the presence of giant bilateral renal masses with the typical appearance of an angiomyolipoma, and a huge retroperitoneal haematoma extending to the pelvis and the left side of the abdomen (fig 1). After arterial embolisation, left radical nephrectomy was performed. The pathological diagnosis was angiomyolipoma without malignant findings, and the patient was discharged two weeks after the operation (fig 2).

During the latest admission, computed tomography of the abdomen showed a giant right renal angiomyolipoma (fig 3). An attempt for selective arterial embolisation failed, and right radical nephrectomy was performed as the patient was becoming haemodynamically unstable. The patient has been started on haemodialysis, and renal transplantation is planned

Kidneys can be involved in three different ways in tuberous sclerosis: angiomyolipomas, cystic disease, and renal cell carcinomas. ${ }^{1}$ The typical angiomyolipoma is a mixture of smooth muscle, fat, and abnormal blood vessels, the relative proportions of which vary widely. ${ }^{1}$ Although angiomyolipomas were previously considered to be hamartomas, they have been recently recognised as clonal neoplasms, and it has been proposed that the perivascular epithelioid cell is the progenitor cell. ${ }^{2}$ From the clinical point of view, angiomyolipomas are usually silent, but they can rarely cause life threatening haemorrhage. Patients with tuberous sclerosis and angiomyolipomas greater than $4 \mathrm{~cm}$ have a high risk of developing symptoms and may require surgery. ${ }^{1}$ Because of its sensitivity in detecting small amounts of fat, computed tomography is the imaging modality of choice, although the typical appearance may be altered in predominantly non-fatty angiomyolipomas or in tumours in which haemorrhage has occurred. Long term follow up results of patients with angiomyolipomas treated with selective arterial embolisation have been reported recently. ${ }^{3}$ Selective arterial embolisation seems to be ideal in the case of acute haemorrhage in selected patients with renal angiomyolipoma but its indication, safety, and efficacy require further evaluation.

G K Anagnostopoulos*, O Doriforou†, G Sakorafas $\ddagger$, S Missas† Departments of Internal Medicine*, Radiology†, and Surgery $\ddagger$, 251 Hellenic Air Force and Veterans General Hospital, Athens, Greece

Correspondence to: Dr Anagnostopoulos; gkanagnostopoulos@yahoo.gr

\section{REFERENCES}

1 Steiner MS, Goldman SM, Fischman EK, et al. The natural history of renal angiomyolipoma. J Urol 1993; 150:1782-6.

2 Katar MM, Grignon DJ, Eble JN, et al. Chromosomal analysis of renal angiomyolipoma by comperative genomic hybridization: evidence for clonal origin. Hum Pathol 1999;30:295-9.

3 Han YM, Kim JK, Roh BS, et al. Renal angiomyolipoma: selective arterial embolization-effectiveness and changes in angiomyogenic components in long-term follow-up. Radiology 1997;204:65-70. 